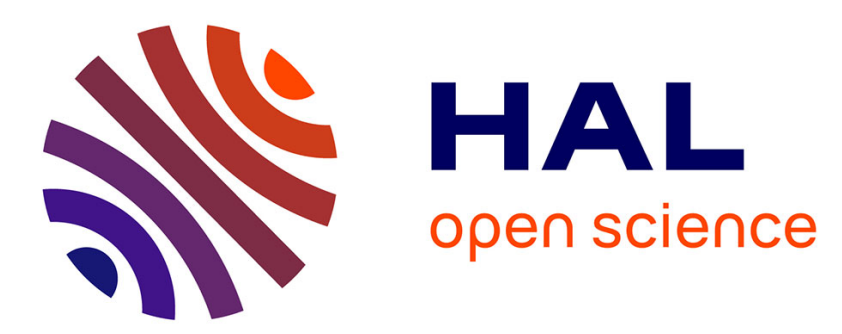

\title{
Evaluation of the Performance of a New Biodegradable AA-LDHI in Cyclopentane Hydrate and $\mathrm{CH} / \mathrm{CH}$ Gas Hydrate Systems
}

Delroisse Henry, Barreto Gilles, Jean-Philippe Torre, Christophe Dicharry, Glénat Philippe

\section{To cite this version:}

Delroisse Henry, Barreto Gilles, Jean-Philippe Torre, Christophe Dicharry, Glénat Philippe. Evaluation of the Performance of a New Biodegradable AA-LDHI in Cyclopentane Hydrate and CH/CH Gas Hydrate Systems. SPE Middle East Oil and Gas Show and Conference, Mar 2019, Manama, Bahrain. 10.2118/195054-MS . hal-02521384

\section{HAL Id: hal-02521384 \\ https://hal-univ-pau.archives-ouvertes.fr/hal-02521384}

Submitted on 27 Mar 2020

HAL is a multi-disciplinary open access archive for the deposit and dissemination of scientific research documents, whether they are published or not. The documents may come from teaching and research institutions in France or abroad, or from public or private research centers.
L'archive ouverte pluridisciplinaire HAL, est destinée au dépôt et à la diffusion de documents scientifiques de niveau recherche, publiés ou non, émanant des établissements d'enseignement et de recherche français ou étrangers, des laboratoires publics ou privés. 


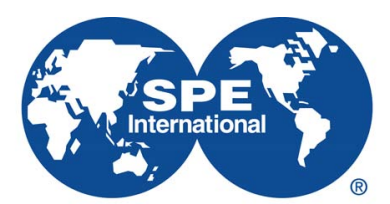

Society of Petroleum Engineers

\title{
SPE-195054-MS
}

\section{Evaluation of the Performance of a New Biodegradable AA-LDHI in Cyclopentane Hydrate and $\mathrm{CH}_{4} / \mathrm{C}_{3} \mathrm{H}_{8}$ Gas Hydrate Systems}

\author{
Delroisse Henry and Barreto Gilles, Arkema; Torré Jean-Philippe and Dicharry Christophe, CNRS/TOTAL/UNIV \\ PAU \& PAYS ADOUR/E2S UPPA, Laboratoire des Fluides Complexes et leurs Réservoirs-IPRA, \\ UMR5150 - avenue de I'Université; Glénat Philippe, Total S.A. \\ Copyright 2019, Society of Petroleum Engineers \\ This paper was prepared for presentation at the SPE Middle East Oil and Gas Show and Conference held in Manama, Bahrain, 18-21 March 2019. \\ This paper was selected for presentation by an SPE program committee following review of information contained in an abstract submitted by the author(s). Contents \\ of the paper have not been reviewed by the Society of Petroleum Engineers and are subject to correction by the author(s). The material does not necessarily reflect \\ any position of the Society of Petroleum Engineers, its officers, or members. Electronic reproduction, distribution, or storage of any part of this paper without the written \\ consent of the Society of Petroleum Engineers is prohibited. Permission to reproduce in print is restricted to an abstract of not more than 300 words; illustrations may \\ not be copied. The abstract must contain conspicuous acknowledgment of SPE copyright.
}

\section{Abstract}

The main objective of this work is to evaluate the performance of a readily biodegradable anti- agglomerant, called AA-LDHI, not harmful for the environment following the European legislation. It was tested in cyclopentane $(\mathrm{CP})$ hydrate and methane $\left(\mathrm{CH}_{4}\right)$ /propane $\left(\mathrm{C}_{3} \mathrm{H}_{8}\right)$ hydrate systems. The performance of AALDHI was first tested in a batch reactor by torque measurements with the two hydrate systems in oildominated conditions $\left(70 \mathrm{vol} \%\right.$ ). The experiments were performed for a subcooling of $6{ }^{\circ} \mathrm{C}$ for the $\mathrm{CP}$ hydrate and up to $17^{\circ} \mathrm{C}$ for the gas hydrate. The impact of AA-LDHI on hydrate growth pattern and on hydrate crystal morphology were investigated by microscopic observations at the water/CP interface for the CP-hydrate system, and at a water/(n-octane $\left.+\mathrm{CH}_{4} / \mathrm{C}_{3} \mathrm{H}_{8}\right)$ interface for the gas hydrate system. Then, AALDHI was evaluated in a semi-industrial flow loop.

Without surfactant, the hydrate formed a polycrystalline shell at the water/oil interface. With AA- LDHI, large conical hydrate crystals with the vertex pointing to the aqueous phase grew at the interface before sinking in the aqueous phase. The results obtained with both CP and gas hydrates are consistent amongst themselves.

In the batch reactor experiments without surfactant, hydrate crystallization led to a significant increase in the torque value and finally to the blockage of the agitator. With AA-LDHI, the torque remained almost constant at the baseline showing that this AA presented good anti-agglomeration performance. The microscopic observation in a $\mathrm{CP}$ phase of CP-hydrate particles formed in the reactor showed large waterwettable particles (about $400 \mu \mathrm{m}$ ) gathered in clusters but not agglomerated.

AA performance of AA-LDHI was also evaluated in a semi-industrial flow loop (1-inch diameter \& 35.6 m total length) in similar conditions with $\mathrm{CH}_{4} / \mathrm{C}_{3} \mathrm{H}_{8}$ mix gas but using real condensate. This experiment proved that the AA-LHDI is fully efficient in transporting safely hydrates.

\section{Introduction}

Gas hydrates are non-stoichiometric crystalline structures composed of water (called hosts) molecules forming cavities of different sizes that encage other molecules (called guests). The guests are usually light 
$\mathrm{C} 1-\mathrm{C} 4$ hydrocarbon molecules. Gas hydrates formation usually requires low temperature (a few degrees above $0{ }^{\circ} \mathrm{C}$ ) and high-pressure (a few $\mathrm{MPa}$ ) conditions. These conditions are encountered in oil and gas production where their formation may plug the pipelines and cause production shutdowns, which result in economic losses and safety problems ${ }^{1}$.

Chemical additives are used to prevent the hydrate plug risk. ${ }^{2}$ Two main families can be distinguished: thermodynamic hydrate inhibitors (THIs), which are used up to several dozen $w \mathrm{t} \%$ relative to the water phase, and low dosage hydrate inhibitors (LDHIs), usually added at less than $1 \mathrm{wt} \%$, to achieve good protection against the hydrate risk. LHDIs include kinetic hydrate inhibitors (KHIs), which delay hydrate nucleation and/or reduce hydrate growth rate, and anti-agglomerants (AAs), which prevent the agglomeration of hydrate crystals.

Cyclopentane (CP) forms with water a sII hydrate at atmospheric pressure and moderately low temperatures (lower than $7.2{ }^{\circ} \mathrm{C}^{3}$ ). $\mathrm{CP}$ hydrates are commonly used to study the performance of $\mathrm{AAs}^{4-6}$ because they are an interesting analog of the structure II gas hydrates for a first evaluation of antiagglomerant properties of surfactants..$^{5,6}$

AAs are amphiphilic molecules and have an interfacial activity (they position themselves at the interfaces). Most of them are composed of a hydrophilic head group and a lipophilic carbon tail. Their presence at the interfaces water/oil, water/gas and water/hydrate impacts the growth of gas hydrates crystals. Thus, several authors studied the influence of surfactants on CP hydrates ${ }^{6-9}$ and/or gas hydrates ${ }^{8-10}$ morphology. Various morphologies were observed such as polygonal crystals, hollow conical crystals8, needles ${ }^{10}$ or pyramidal crystals. ${ }^{9}$ The configuration of the adsorbed AA molecules on the hydrate surface will impact the crystal wettability: (i) with a lying-down configuration, with both the headgroup and alkyl chain tail close to the hydrate surface, the crystal will be hydrophobic, (ii) the same will occur for a headdown configuration, with the headgroup attached to the hydrate surface and the lipophilic tail oriented away from it, and (iii) with a bilayer configuration, with the head groups of the second layer oriented away from the hydrate surface and the alkyl chain tails of both surfactant molecule layers are attached by hydrophobic interaction, the crystal will be hydrophilic. ${ }^{11}$ Depending on the surfactant, the hydrates crystals can be highly hydrophobic, ${ }^{7}$ with molecules in head-down or lying down configuration, or hydrophilic ${ }^{9}$ in bilayer configuration.

AA performance of a molecule can be evaluated in laboratory on agitated reactor. The agglomeration state of the hydrates formed is evaluated by torque measurements and/or by direct observations by sapphire windows. Rocking cells in steel or sapphire can also be used. Steel balls provide agitation in the cells and are stopped when the hydrates form plug. With both apparatus, hydrates at atmospheric pressure ${ }^{5,12,13}$ or high pressure gas hydrates ${ }^{5,14}$ can be formed. Flow loops can also be employed. They are composed of a high pressure pipe forming a loop in which the gas hydrates forming system circulates thanks to a pump. They allow more accurate experimental conditions compared with real cases of hydrocarbon phase flow in a pipelines. The agglomeration state of the hydrates is evaluated by the pressure loss measurement in the system. ${ }^{15-17}$ Additional experiments, such as for example interfacial tension measurements ${ }^{18}$, microscopic observations ${ }^{8,9}$, micromechanical force measurements ${ }^{18}$, can also be used for better understanding of the agglomeration mechanisms in the presence of AAs.

In the present work, we first studied and compared the effects of a readily biodegradable anti-agglomerant on the morphology and wettability of hydrate crystals formed with $\mathrm{CP}$ (at atmospheric pressure) and a $\mathrm{CH}_{4} / \mathrm{C}_{3} \mathrm{H}_{8}$ gas mixture (at about 70 bar). Then, the AA performance of the molecule was evaluated with both hydrate systems. The hydrate crystal morphology was determined by microscopic observations at a quiescent water/oil interface, and the AA performance was studied in an agitated reactor for oil-dominated systems containing $30 \mathrm{vol} \%$ of aqueous solution. The correlations between the hydrate morphology, the wettability of the hydrate crystals formed and the AA performance of the surfactant obtained for both hydrate 
systems were discussed. At a final stage, the AA performance was also evaluated in a semi-industrial flow with real hydrocarbons which confirmed full efficiency.

\section{Experimental section}

Materials. Cyclopentane (98\% reagent grade), n-octane (99\% pure, referred to as n-C8) and n- dodecane (99\% pure, referred to as n-C12) were supplied by Acros Organics. "Ultra pure" water (resistivity of 18.2 M $\Omega . c m)$, produced by a laboratory water-purification system from Purelab, was used to prepare the surfactant solutions. The hydrate-forming gas was a binary mixture of methane $\left(\mathrm{CH}_{4}\right)$ and propane $\left(\mathrm{C}_{3} \mathrm{H}_{8}\right)$ supplied by Linde. Two ratios were used $84 / 16 \mathrm{~mol} \%$ and $98 / 2 \mathrm{~mol} \%$ of $\mathrm{CH}_{4} / \mathrm{C}_{3} \mathrm{H}_{8}$ (relative uncertainty of $\pm 2 \%$ ). The anti-agglomerant additive used in the study was patented ${ }^{19}$ and is called AA-LDHI. It is readily biodegradable using the OECD 301 method. All the concentrations of AA-LDHI given in the work are in $\mathrm{wt} \%$ in the aqueous phase.

Microscopic observation of hydrate formation. $\mathrm{CP}$ hydrates. $\mathrm{CP}$-hydrate growth and morphology were studied by microscopic observations of the interface between the water and CP phases. The CP and water were introduced in a cylindrical glass tube placed in a metallic jacketed vessel in which a water- glycol mixture circulated to control the temperature (Figure 1, Device 1). The details of the experimental setup can be found in a previous study 6 . In brief, aqueous solution $\left(5 \mathrm{~cm}^{3}\right)$ (without or with $0.1 \mathrm{wt} \%$ AA- LHDI) and $\mathrm{CP}\left(3 \mathrm{~cm}^{3}\right)$ were introduced in the glass tube. Then, the temperature of the system was decreased to $1.0{ }^{\circ} \mathrm{C}$ (equilibrium temperature of $\mathrm{CP}$ hydrates, $\mathrm{T}_{\text {eq }}=7.2 \pm 0.2{ }^{\circ} \mathrm{C}$ ) Once at $1.0{ }^{\circ} \mathrm{C}\left(\Delta \mathrm{T}_{\text {sub }}=6{ }^{\circ} \mathrm{C}\right)$, the crystallization was triggered by seeding the system with a few small CP-hydrate crystals formed in advance. The hydrate growth was recorded with a CDD camera.

$\mathrm{CH}_{4} / \mathrm{C}_{3} \underline{\mathrm{H}_{8}} \underline{\text { hydrates. The }} \mathrm{CH}_{4} / \mathrm{C}_{3} \mathrm{H}_{8}$ gas hydrate growth and morphology were studied in a jacketed highpressure cell, made of 316 stainless steel, with an internal volume of $17 \mathrm{~cm}^{3}$. The details of the experimental setup and proceedings can be found in a previous study ${ }^{6}$. A schematic diagram of the experimental setup is detailed in Figure 1 (Device 2). In brief, the cell is equipped with two sapphire windows, and contains a horizontal tray covered with a Teflon tape and a vertically moveable capillary, which is connected to a syringe pump (Isco 100DM) used to form a drop of the aqueous phase at the tip of the capillary. The system is lit by a led ring light and the imaging system is composed of a binocular magnifier equipped with a CCD camera (IDS UI124xSE-C).

The cell was filled with n-C8 $\left(9 \mathrm{~cm}^{3}\right)$ and cooled down to $5.4{ }^{\circ} \mathrm{C} . \mathrm{CH}_{4} / \mathrm{C}_{3} \mathrm{H}_{8}$ gas mixture was loaded at 70 bar (in these conditions, $\Delta \mathrm{T}_{\text {sub }} \sim 10^{\circ} \mathrm{C}$ ). The surfactant solution in the capillary tube, which connects the syringe pump and the cell, was frozen by pouring liquid nitrogen on it. The pressure in the syringe pump was increased of a few bar to create an overpressure on the ice plug formed in the tube. As soon as the ice plug was melted, a drop was formed at the tip of the capillary with the pump. The drop was then deposited on the horizontal tray. Hydrate formation was triggered by using the "memory effect" after the dissociation of the ice. Snapshots of the hydrate crystallization and growth were recorded at regular time steps. The experiments were performed at a surfactant concentration of $0.1 \mathrm{wt} \%$. 


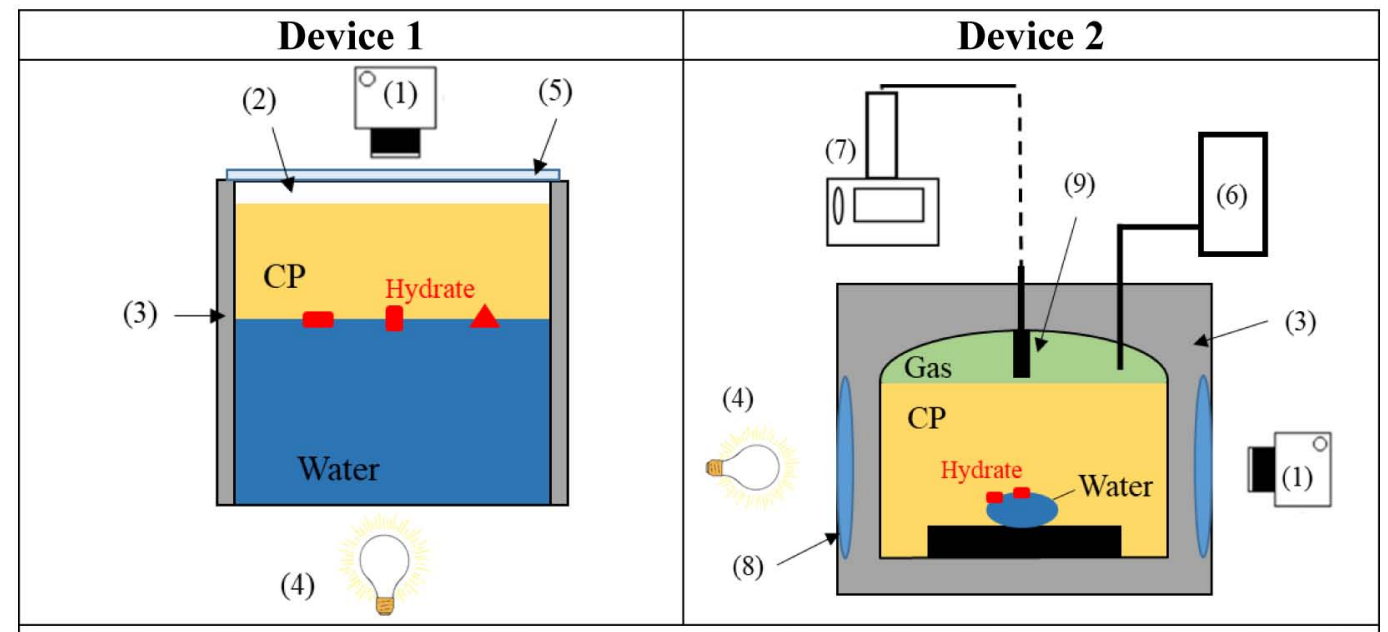

(1) Binocular magnifier with camera; (2) glass tube (diameter $28 \mathrm{~mm}$ ); (3) metallic jacketed vessel connected to a chiller; (4) LED light; (5) glass cup (6) gas storage tank; (7) Isco pump; (8) sapphire windows; (9) capillary.

Figure 1-Schematic diagrams of the experimental setups used for the experiments conducted at atmospheric (Device 1) and high pressure (Device 2).

Evaluation of anti-agglomeration performance. The performance of the AA-LHDI was evaluated with a stirred-tank reactor and details of the experimental setup are presented in a previous publication. ${ }^{6}$ In brief, the reactor is a jacketed high-pressure reaction made of 316 stainless steel with a volume of $360 \pm 3 \mathrm{~cm}^{3}$. It is equipped with a four blades turbine driven by an $\mathrm{AC}$ motor. A torque-meter is placed on the stirring shaft, the maximum torque delivered by the agitator motor is 0.7 N.m.

$\mathrm{CP}$ hydrates. The reactor contains an extractable cylindrical glass vessel of $300 \mathrm{~cm}^{3}$ filled with pure water $\left(45 \mathrm{~cm}^{3}\right)$ or surfactant solution (1 wt $\left.\% \mathrm{AA}-\mathrm{LDHI}\right)$, and with CP $\left(105 \mathrm{~cm}^{3}\right)$ (water-cut of $\left.30 \mathrm{vol} \%\right)$. The agitation was set to 200 RPM, and the system was cooled to $1{ }^{\circ} \mathrm{C}$. Once the system temperature stabilized, agitation was stopped and the reactor briefly opened and seeded with a few CP-hydrate crystals formed previously. The reactor was then shut again, and agitation restarted. The onset of the hydrate formation was detected owing to an increase in the reactor temperature. When the reactor temperature reached the target temperature again, the experiments were stopped, and the reactor opened to collect samples of the oil phase and of the hydrate particles. The hydrate particles were quickly incorporated into cold $\mathrm{CP}\left(0^{\circ} \mathrm{C}\right)$ and observed by microscopy to determine their shape, diameter, agglomeration state, and wettability.

$\mathrm{CH}_{4} / \mathrm{C}_{3} \underline{H}_{8}$ hydrates. The cylindrical glass vessel was filled with pure water $\left(36 \mathrm{~cm}^{3}\right)$ or surfactant solution (at $1 \mathrm{wt} \%$ AA-LDHI) and with $\mathrm{n}-\mathrm{C} 8\left(84 \mathrm{~cm}^{3}\right)$ (water-cut of $30 \mathrm{vol} \%$ ). The reactor was then pressurized with the $\mathrm{CH}_{4} / \mathrm{C}_{3} \mathrm{H}_{8}$ gas mixture to an equilibrium pressure of $70 \pm 1$ bar under agitation $(200 \mathrm{RPM})$ at $25^{\circ} \mathrm{C}$. In these condition the equilibrium conditions of the hydrate are $\mathrm{P}_{\text {eq }}=67 \pm 1 \mathrm{bar}$ and $\mathrm{T}_{\mathrm{eq}}=18.6 \pm 0.5^{\circ} \mathrm{C} .{ }^{6}$ The system was kept under agitation for 2 hours at $25^{\circ} \mathrm{C}$. The agitation was then stopped, and the system was cooled to $2{ }^{\circ} \mathrm{C}$ at a rate of $0.3{ }^{\circ} \mathrm{C} / \mathrm{min}$. When the system temperature and pressure were stable, agitation was resumed (200 RPM). Hydrate crystallization was detected owing to an increase in the system temperature and a decrease in the system pressure due to gas being consumed by the forming hydrate phase.

Water-to-hydrate conversion. The methods used to evaluate the water-to-hydrate conversion are the same as those described by Delroisse et al. (2018). ${ }^{6}$ For CP hydrates, it was evaluated by gas chromatography, by determinating the variation of the concentration of a small amount ( $2 \mathrm{wt} \%)$ of $\mathrm{n}-\mathrm{C} 12$ used as a chemical marker in the $\mathrm{CP}$ phase. $\mathrm{n}-\mathrm{C} 12$ is not soluble in water and does not form gas hydrates. It was used at a sufficiently low concentration in the CP phase $(2 \mathrm{wt} \%)$ to prevent a significant shift of the CP-hydrate equilibrium temperature. Samples of the oil phase were collected at the same time as CPhydrate particles. 
For the $\mathrm{CH}_{4} / \mathrm{C}_{3} \mathrm{H}_{8}$ hydrates, the water-to-hydrate conversion (molar basis) was determined from the variation of pressure measured before and after the hydrate formation. GC analyses of the gas mixture were also done before the hydrate formation and after the end of the formation to determine the $\mathrm{CH}_{4}: \mathrm{C}_{3} \mathrm{H}_{8}$ ratio.

Hydrate flow loop testing facility. The details of one of the Total Flow Loop facility are given elsewhere, ${ }^{17}$ though a short description is given here. A simplified scheme and a photograph of the hydrate loop are shown in Figure 2 and Figure 3. It allows to flow gas saturated hydrocarbon liquids in a closed loop. The unit mainly consists in a pipe (1-inch diameter \& $35.6 \mathrm{~m}$ total length), a Moineau type pump and a storage tank. The shape of the loop is a double vertical ring of $32 \mathrm{~m}$ linked to the inlet/outlet of the pump. The whole pipe is jacketed in order to control its temperature via the circulation of a cooling/heating fluid inside the jacket. It is designed to circulate fluids at a pressure as high as 165 bar and a temperature ranging from 40 to $-10{ }^{\circ} \mathrm{C}$. The main parameters recorded are: density, flow mass, pressure drops, temperature changes, gas flow (to keep constant P). In the tests presented here, a real Middle East condensate was used together with a $\mathrm{CH}_{4} / \mathrm{C}_{3} \mathrm{H}_{8}(98 / 2 \mathrm{~mol} \%)$ hydrate-forming gas. Results obtained with this flow loop have been shown to be well correlated with other testing equipments. ${ }^{20}$

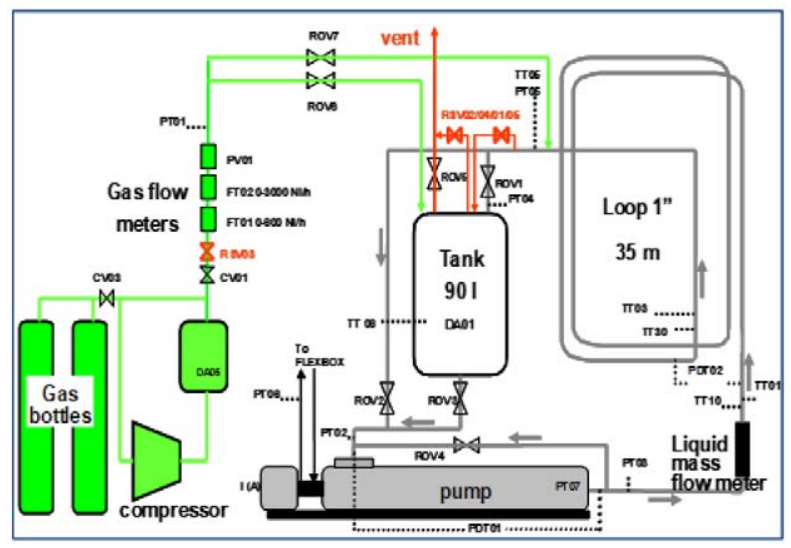

Figure 2-Simplified flow scheme of the 165 bar hydrate loop.

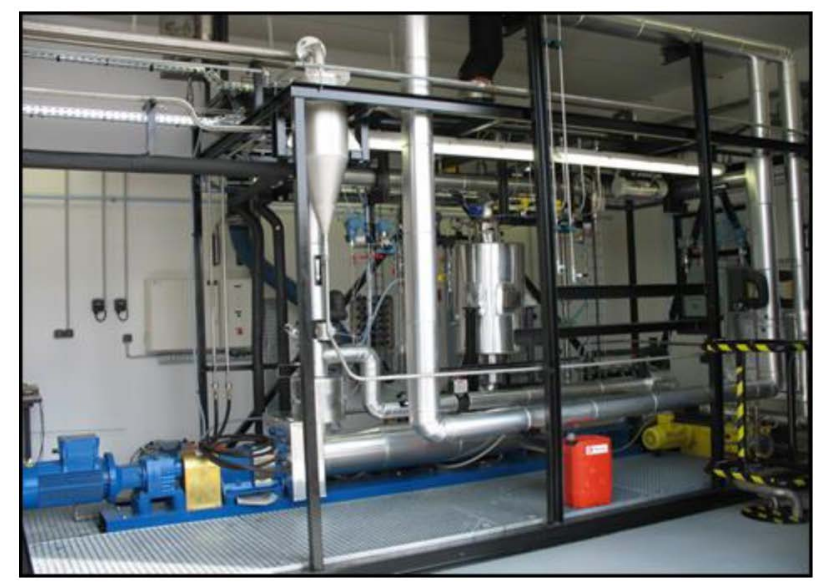

Figure 3-Photograph of the 165 bar hydrate loop.

Test performed consist in simulating a restart after a shut-down, i.e. condensate + gas + water $+\mathrm{AA}$ LDHI are first flown at $20^{\circ} \mathrm{C}$ and 50 bar to homogeneize and saturate the emulsion. Then flow is stopped and the system is cooled down to $0.5^{\circ} \mathrm{C}$ at a rate of $10^{\circ} \mathrm{C} / \mathrm{h}$ and remains overnight at this temperature, before flow is resumed. Hydrates start to form instantaneously and are then transported during 6 hours. The water-cut was of $50 \%$, using water at $1 \mathrm{~g} / \mathrm{dm}^{3} \mathrm{NaCl}$ at a dose of $3 \mathrm{wt} \%$ AA-LDHI, at a constant pressure of 50 bar and $9^{\circ} \mathrm{C}$ of subcooling. 
Interfacial Tension (IFT) Measurements. IFT measurements were performed using a dynamic drop tensiometer. A CP drop was formed and maintained vertically at the top of an inverted needle in a transparent thermostated cell containing the aqueous phase. All experiments were performed at $1{ }^{\circ} \mathrm{C}$. The volume of the drop was adjusted to reach a Laplacian profile. Images of the drop were recorded in real time with a CCD camera.

\section{Results and discussions}

\section{Microscopic observation of hydrate formation}

Water/CP system. CP-hydrate formation was observed on a system without surfactant. Figure 4 shows a picture of the hydrate formed. The hydrate crystals grew and propagated at the water/CP interface at a rate of $0.21 \pm 002 \mathrm{~mm} / \mathrm{min}^{9}$, where they formed a thin polycrystalline layer as already reported in the literature ${ }^{7,21}$.

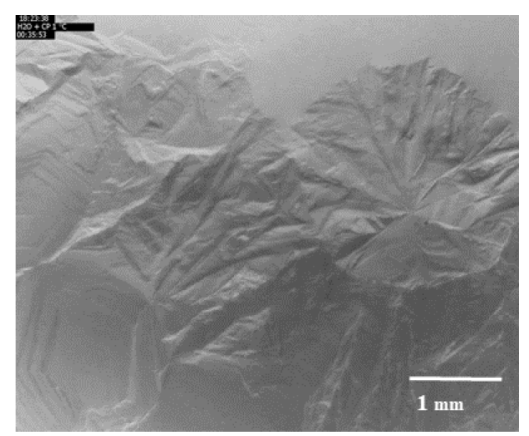

Figure 4-Snapshot of CP-hydrate growth at the water/CP interface without surfactant, at a subcooling of $6^{\circ} \mathrm{C}$ at $40 \mathrm{~min}$. The initial time $(\mathrm{t}=0 \mathrm{~min})$ corresponds to the seeding.

(Water + AA-LDHI)/CP system. CP-hydrate formation was observed on a (water $+0.1 \mathrm{wt} \% \mathrm{AA}$ LDHI)/CP interface (Figure 3).

After the seeding, first crystals grew slowly and formed thin needles which ended up sinking in the aqueous phase. (Figure 5.a and Figure 5.b). Then, large polygonal crystals with a shape of empty cones with the vertex pointing to the aqueous phase appeared (Figure 5.c). They grew by their basis, reaching 1 to $3 \mathrm{~mm}$ in width. Thereafter, water penetrated into the cones by one of their edges, and filled them until they sank under the water/CP interface. The fact the crystals moved from the interface to the aqueous phase, showed thatthe adsorption of AA-LDHI on their surface made them highly hydrophilic. A sequence of this phenomenon is detailed in Figure 6.a to Figure 6.e. Once completely filled (Figure 6.f), a track of the basis of the cone stayed for a moment visible at the interface.

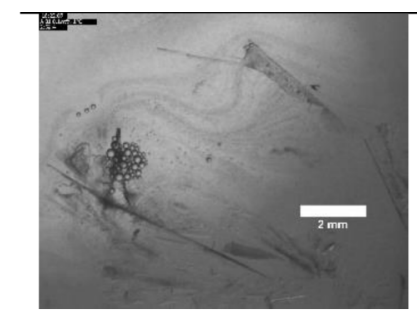

(a) $180 \mathrm{~min}$

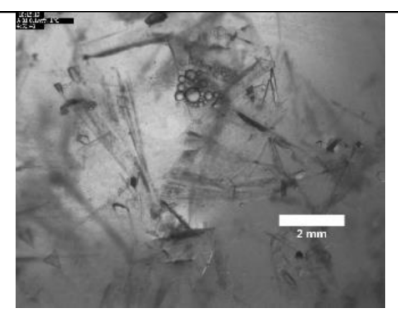

(b) $290 \mathrm{~min}$

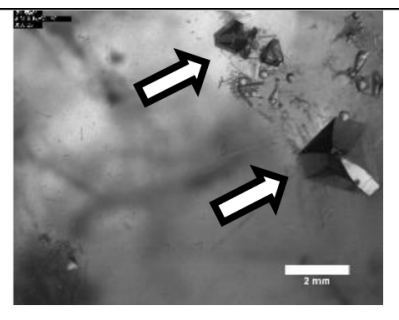

(c) $510 \mathrm{~min}$

Figure 5-Snapshots of CP-hydrate growth at the water/CP interface with $0,1 \mathrm{wt} \% \mathrm{AA}$ $\mathrm{LDHI}$, at a subcooling of $6^{\circ} \mathrm{C}$. The initial time $(\mathrm{t}=0 \mathrm{~min})$ corresponds to the seeding. 


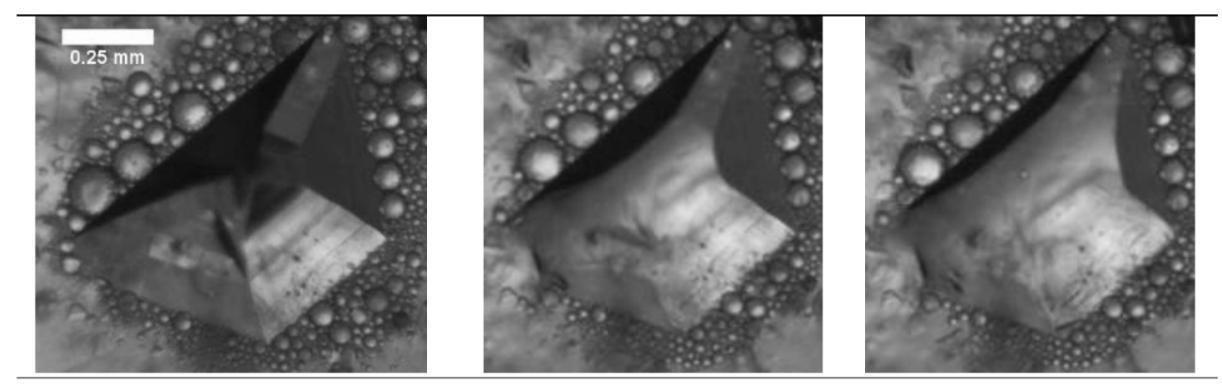

(a) $0 \mathrm{~s}$

(b) $10 \mathrm{~s}$

(c) $17 \mathrm{~s}$

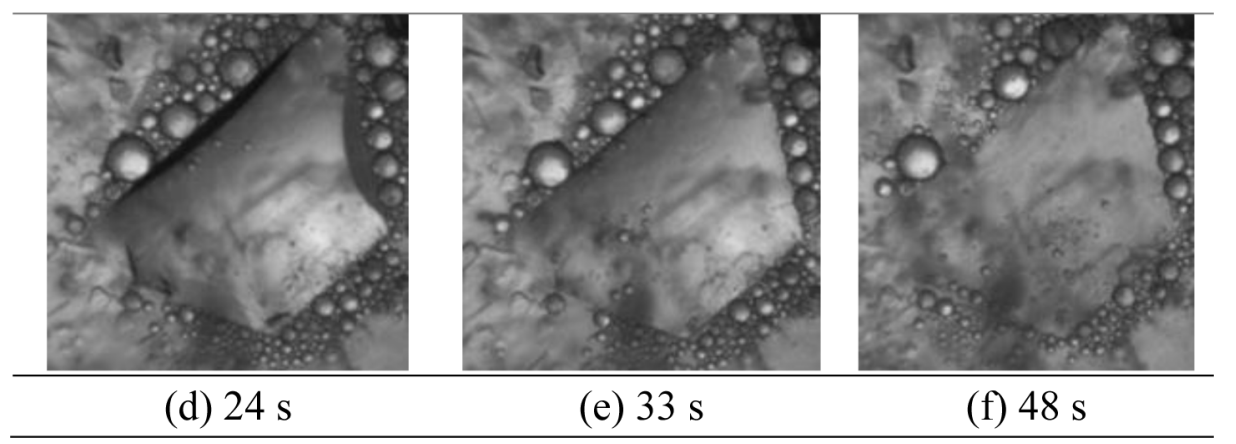

Figure 6-Follow-up of the filling of a crystal cone by the AA-LDHI aqueous solution.

The emulsion drops visible on the pictures formed when the crystals sank. They are composed of CP because they rose to the surface when the crystals sank. Afterwards, news conical crystals formed in the interface and pushed the older more deeply in the aqueous phase. The phenomenon was repeated until all the aqueous phase was filled by crystals (in about 14 hours for our system).

Water/n-C8/ $\mathbf{C H}_{4}-\mathbf{C}_{3} \mathbf{H}_{8}$ system. Figure 7 shows the pictures of the hydrate formation at the water/n- C8/ $\mathrm{CH}_{4}-\mathrm{C}_{3} \mathrm{H}_{8}$ interface. Once the drop was seeded and deposited on the tray, small crystals dispersed in the drop moved to its top. The hydrates then grew from the top to the bottom of the drop, covering it progressively with a thin wrinkled shell (Figure 7.a to Figure 7.c).

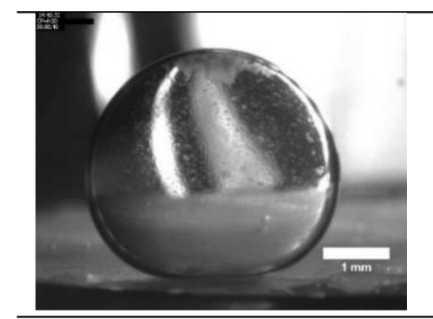

(a) $1 \mathrm{~min}$

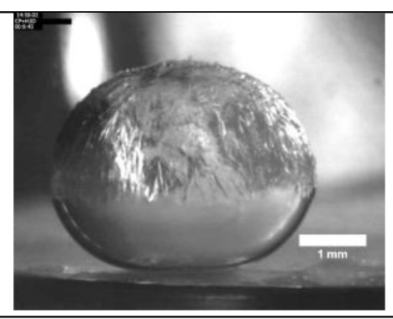

(b) $10 \mathrm{~min}$

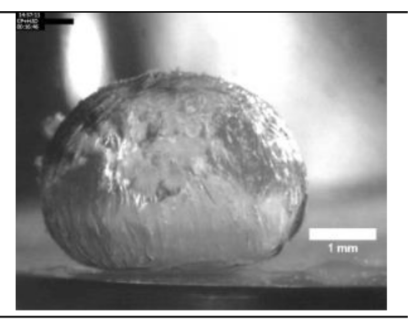

(c) $17 \mathrm{~min}$

Figure 7-Formation of the gas hydrate on a drop of pure water in $\mathrm{n}-\mathrm{C} 8$ at 66 bar of $\mathrm{CH}_{4} / \mathrm{C}_{3} \mathrm{H}_{8}$, at a subcooling of $6{ }^{\circ} \mathrm{C}$.

(Water + AA-LDHI)/n-C8/ $\mathbf{C} \mathbf{H}_{4}-\mathbf{C}_{3} \mathbf{H}_{\mathbf{8}}$ system. With $0.1 \mathrm{wt} \%$ AA-LDHI, conical crystals with their vertex pointing in the aqueous phase formed at the water/n-C8 interface (Figure 8). As observed with $\mathrm{CP}$ hydrates, the crystals sank in the drop, confirming AA-LDHI made the crystals highly water-wettable. At the same time, crystals formed an "island" on the top of the drop, which then moved along the water/nC8 interface (Figure 9.a to Figure 9.c). This island developed in the aqueous phase until all the water was converted in hydrate (Figure 9.d to Figure 9.f), showing the structure was porous. 


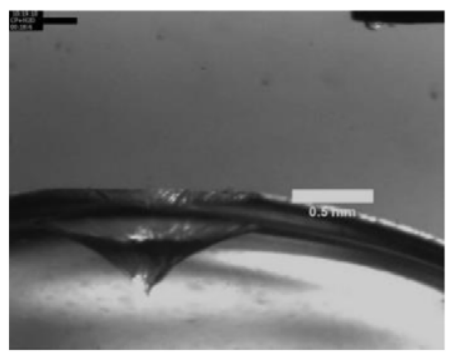

Figure 8-Conical gas hydrate crystal formation with 0.1 wt $\%$ AA-LDHI, in $n-C 8$ at 66 bar of $\mathrm{CH}_{4} / \mathrm{C}_{3} \mathrm{H}_{8}$, at a subcooling of $10{ }^{\circ} \mathrm{C}$.

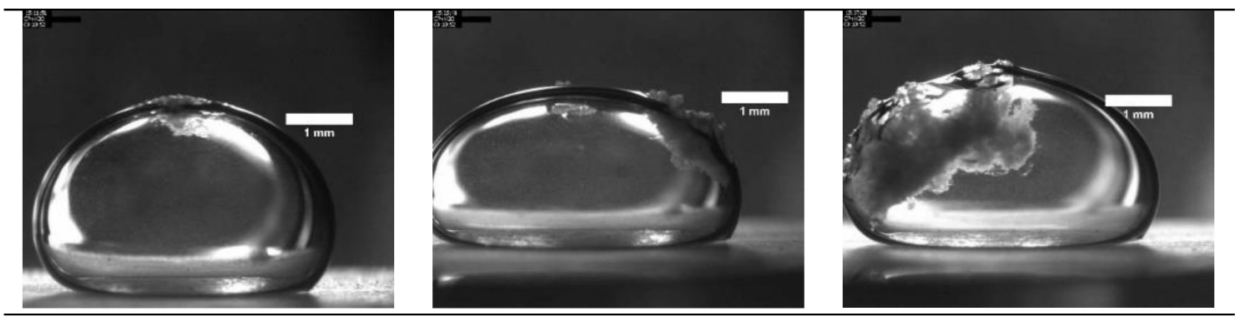

(a) $0 \mathrm{~min}$

(b) $14 \mathrm{~min}$

(c) $26 \mathrm{~min}$
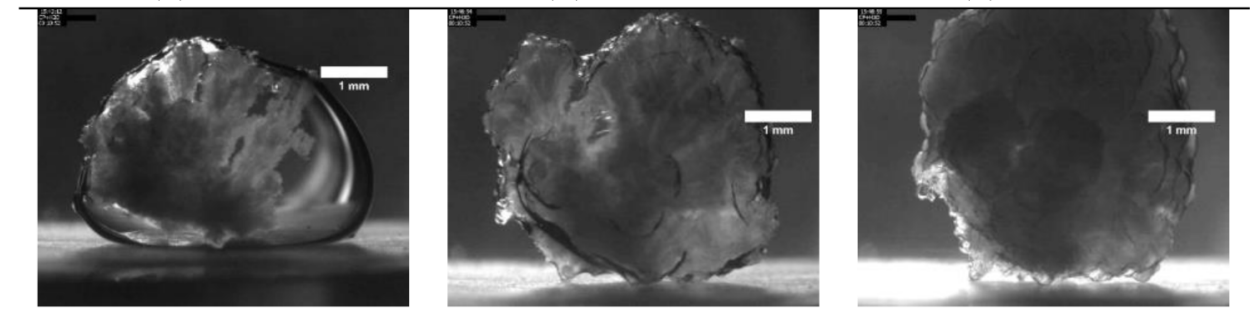

(d) $31 \mathrm{~min}$

(e) $36 \mathrm{~min}$

(f) $38 \mathrm{~min}$

Figure 9-Gas hydrates formation on a drop of aqueous solution of 0.1 wt $\%$ AA-LDHI, in $\mathrm{n}-\mathrm{C} 8$ at 66 bar of $\mathrm{CH}_{4} / \mathrm{C}_{3} \mathrm{H}_{8}$, at a subcooling of $10^{\circ} \mathrm{C}$.

The fact that the hydrate is water-wettable indicates that the AA-LDHI molecules are adsorbed in a configuration such as their polar part is oriented outside (so probably in bilayer).

\section{Evaluation of AA performance}

Water/CP system. Figure 10 shows the variation of the torque $(C)$ and temperature $(T)$ versus time $(t)$ for a pure water/CP system in stirred-tank reactor. The seed was added at $140 \mathrm{~min}$ but the "catastrophic" crystallization occurred 200 min later (significant increase of the temperature). Once the hydrate started growing, the torque progressively increased to 0.3 N.m until the agitator seized up at $550 \mathrm{~min}$ (at about 0.7 N.m). At this moment, the agitation stopped and the reactor was opened. The system was composed of a hydrate plug filling the reactor over the entire height of the agitator (Figure 10). No liquid phase was present. This plug made the agitator and the glass tube interdependent. The torque rise was caused by a strong increase of the viscosity after the beginning of the crystallization when hydrate particles agglomerated by the formation of capillary bridges. ${ }^{6,22}$ 


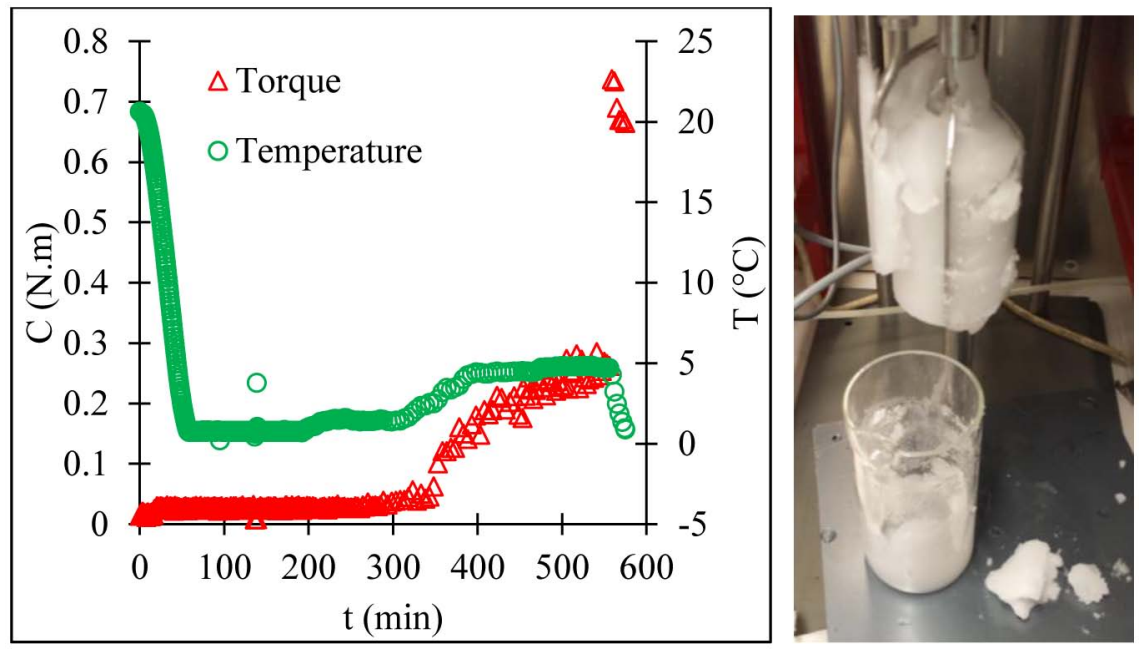

Figure $10-$ Torque $(C)$, temperature $(T)$ versus time $(t)$ during the formation of CP hydrates without surfactant and a picture of the hydrate plug formed.

(Water + AA-LDHI)/CP system. With AA-LDHI, the hydrate formed AND the torque rose slightly from the baseline $(0.025 \mathrm{mN} / \mathrm{m})$ to $0.035 \mathrm{mN} / \mathrm{m}$ (Figure 11). At the end of the experiment, a sample of the system was collected and added in cold CP. The microscopic observation showed hydrate particles with an average diameter of $380 \pm 150 \mu \mathrm{m}$ gathered in clusters in cold CP. A drop of cold AA-LDHI solution added nearby a cluster quickly wetted the particles (Figure 12.b and Figure 12.c)

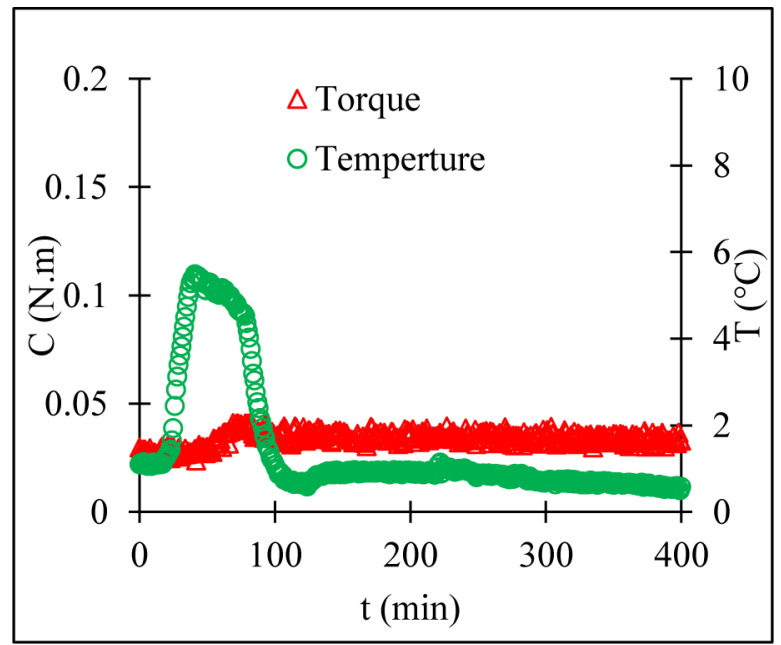

Figure 11-Torque $(C)$, temperature $(T)$ versus time $(t)$ during the formation of CP hydrates with 1 wt $\%$ AA-LDHI.

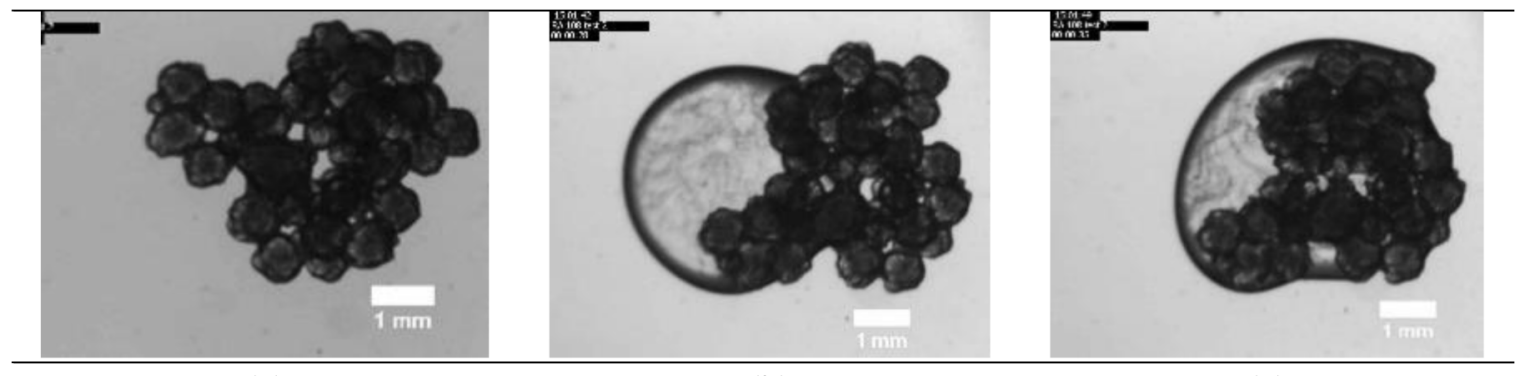

(a)

(b)

(c)

Figure 12-CP-hydrate particles with a 1 wt\% AA-LDHI solution drop (a, b, c). 
These observations confirmed those done by microscopy, namely that the AA-LDHI made the hydrate highly hydrophilic. The GC analysis of the supernatant CP phase revealed that all of the water present in the system was converted to hydrates.

AA-LDHI effectiveness as anti-agglomerant probably results from the ability of the molecules to prevent or limit the formation of capillary bridges between hydrate particles. Anklam et al. (2008) ${ }^{16}$ defined the capillary forces as:

$$
\frac{F_{s}}{a}=2 \pi \gamma \cos \theta_{p}
$$

with Fs capillary force, $a$ particle radius, $\gamma$ the interfacial tension between the water and the oil, $\theta p$ is the contact angle of the water on the hydrate particle. Without surfactant, the hydrate surface is hydrophilic, and the water spreads it involving a high $\theta p$ and a small $\cos \theta_{p}$ value. The capillary forces are proportional to $\gamma$. The interfacial tension between the aqueous phase and the oil was measured lower than $1 \mathrm{mN} / \mathrm{m}$. As $\gamma$ is weak, capillary forces are reduced, hence the particles agglomeration tendency is reduced. This result is consistent with Tayler et al.'s conclusion (2007), ${ }^{23}$ who suggested from adhesion force measurements between hydrophilic tetrahydrofuran-hydrate particles $\left(\cos \theta_{p} \sim 1\right)$ that the decrease of $\gamma$ limits the particle agglomeration. Besides the effect on the interfacial tension between the water and the CP, AA-LDHI molecules adsorbed on the hydrate also generate steric and/or electrostatic repulsions between the particles, taking part in their good dispersion.

Water/n-C8/ $\mathbf{C H}_{4}-\mathbf{C}_{3} \mathbf{H}_{8}$ system. Figure 13. a shows the torque, pressure and temperature variation versus time for the systems without and with $1 \mathrm{wt} \%$ AA-LDHI at a subcooling of about $17^{\circ} \mathrm{C}$. The final values of the water-to-hydrate conversion and the hydrate volume fraction are given in Table 1.
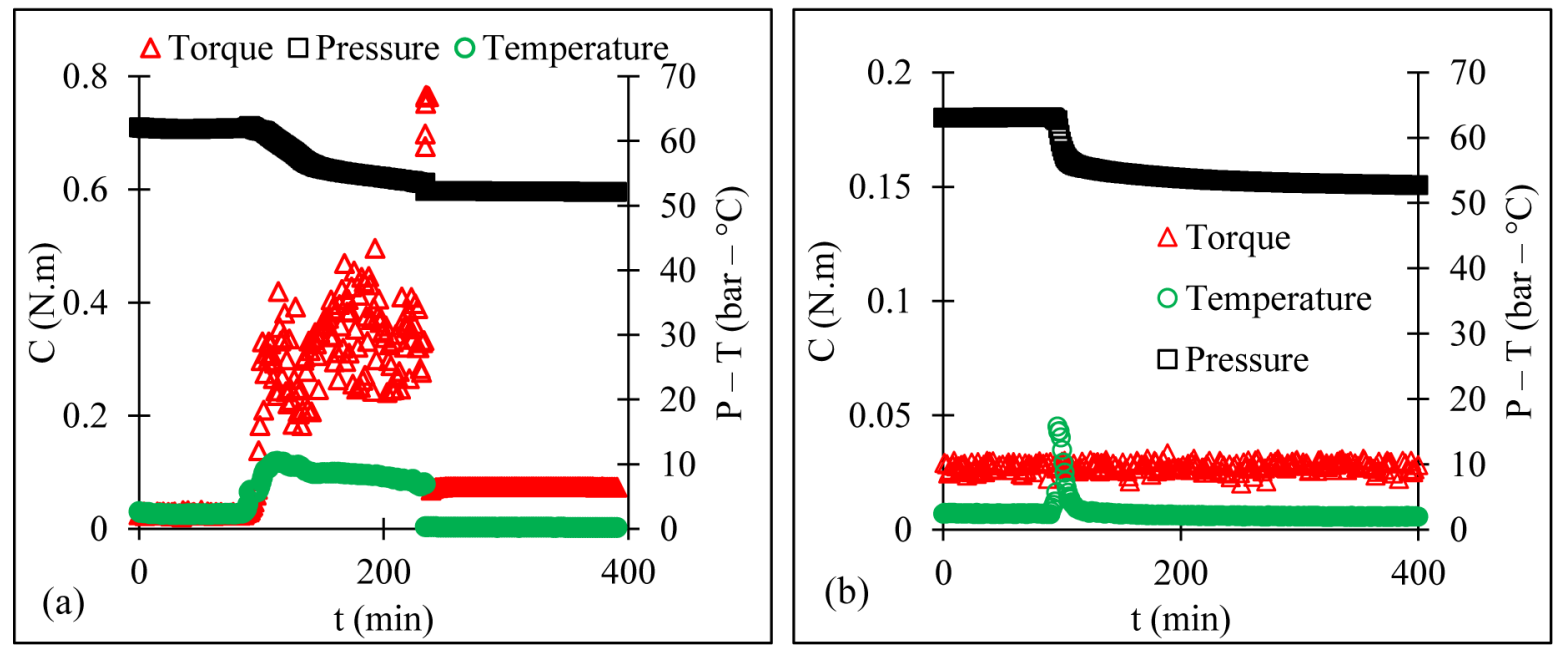

Figure 13-Torque $(C)$, temperature $(T)$, pressure $(P)$ versus time $(t)$ during the formation of gas hydrates without anti-agglomerant (a) and with $1 \mathrm{wt} \%$ AA-LDHI (b) at a subcooling of $17^{\circ} \mathrm{C}$.

Without surfactant, the hydrate crystallization caused a progressive increase of the torque to $0.3-0.4$ N.m which then fluctuated around these values before rising suddenly to 0.7 N.m and blocking the agitator. The torque rise was caused by the frictions between hydrate agglomerates on the agitator and the glass tube and the rapid drop to the baseline might be caused by the breaking of agglomerates into smaller ones. The final hydrate volume fraction was $16 \pm 2 \%$ (Table 1). About $50 \%$ of the water was converted to hydrate. The hydrate formation stopped when all the propane of the gas mixture was trapped in the hydrate. 
Table 1-Water-to-hydrate conversion $(W)$ and hydrate volume fraction $(\Phi)$ without and in the presence of 1 wt $\%$ AA-LHDI.

\begin{tabular}{ccc}
\hline & W (\%) & $\Phi(\% \mathrm{vol})$ \\
\hline Without AA-LHDI & $47 \pm 5$ & $16 \pm 2$ \\
\cline { 2 - 3 } With AA-LHDI & $51 \pm 5$ & $17 \pm 2$ \\
\hline
\end{tabular}

$\left(\right.$ Water + AA-LDHI) $/ \mathbf{n}-\mathbf{C 8} / \mathbf{C H}_{4}-\mathbf{C}_{3} \mathbf{H}_{8}$ system. The hydrate crystallization (from $\mathrm{t}=70 \mathrm{~min}$ ) did not impact the torque which remained constantly at the baseline (Figure 13.b). The hydrate volume fraction $(17 \pm 2 \%)$ was about the same as that for the pure system, for which a large increase in the torque value was observed. Consequently, AA-LHDI has good anti-agglomeration performance as already observed for the CP-hydrate system. The hydrate formation rate was almost 7 times faster than the system without AA. Nevertheless, it did not impact the torque value, which supports the efficiency of this AA.

\section{Performance of the AA-LHDI, bench tests}

Microscopic observations of the hydrate crystal growth at the water/CP and water/n-C8 interface showed the crystals formed in the presence of AA-LHDI remained individuals and did not agglomerate. The same observations were done in the batch reactor experiments. In both systems, the hydrates formed were hydrophilic. The fact the AA-LHDI induced the formation of highly hydrophilic particles and has the good AA performance is different that the literature usually describes, namely a good AA makes hydrate particles hydrophobic. ${ }^{24}$ In a previous study ${ }^{6}$, it was showed that with an ammonium chloride surfactant, individual oil-wettable pyramidal crystals formed at a quiescent water/oil interface and exhibited good antiagglomeration performance. The good anti-agglomerant property of AA-LDHI may be explained here by (i) the reduction of the water/oil IFT, $\gamma<1 \mathrm{mN} / \mathrm{m}$ (water/CP interface), (ii) strong steric and/or electrostatic repulsions. These two parameters allow reducing the capillary forces even if the particles are water wettable.

\section{Performance of the AA-LHDI / flow loop tests}

The AA-LDHI was finally tested using a semi-industrial flow loop using a real condensate and a $\mathrm{CH}_{4} / \mathrm{C}_{3} \mathrm{H}_{8}$ (98/2\% mole) mix gas at a water-cut of 50\% using water at $1 \mathrm{~g} / \mathrm{L} \mathrm{NaCl}$ with $3 \mathrm{wt} \%$ AA-LDHI. Results are presented in Figure 14. 


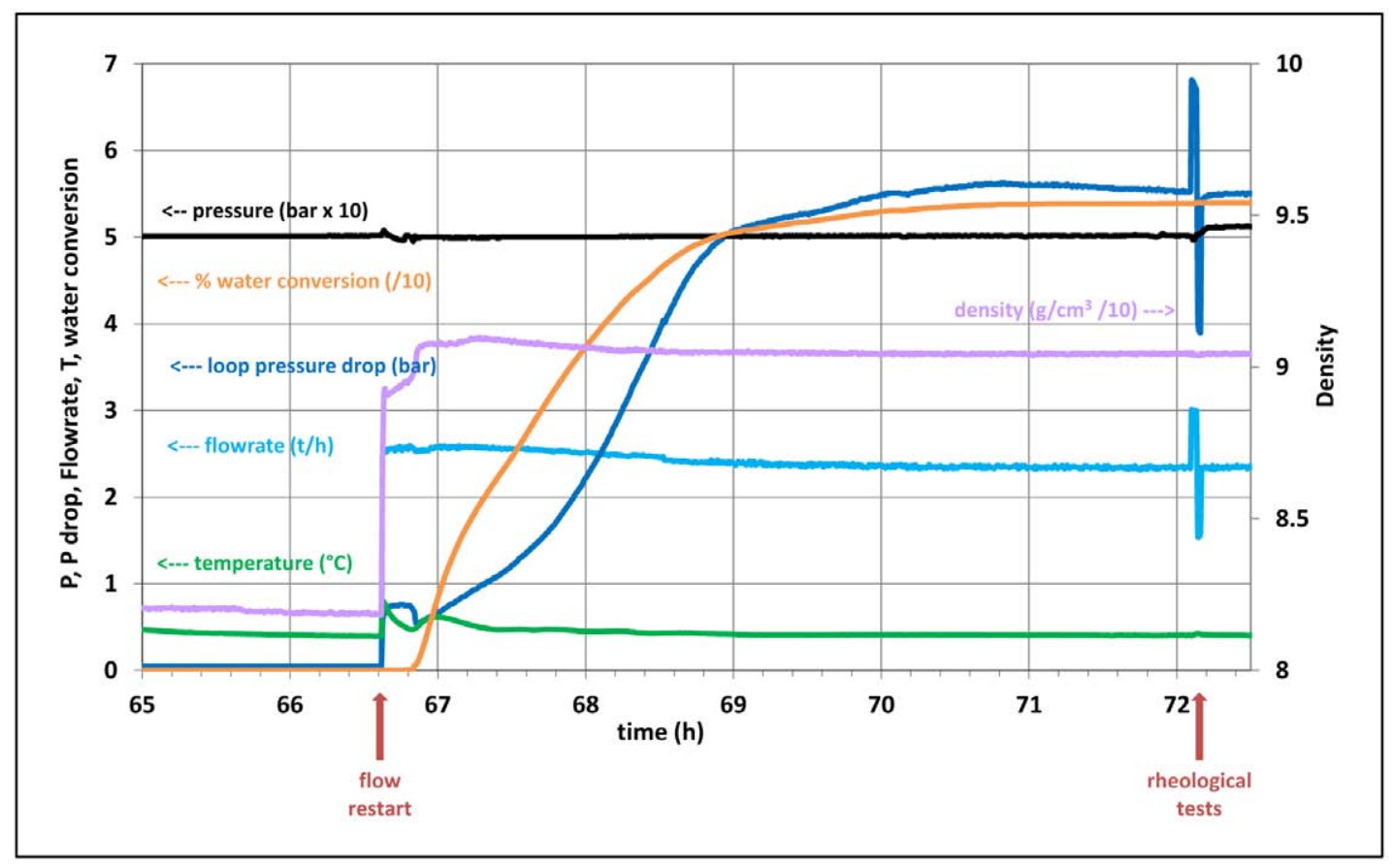

Figure 14-Flowloop test with real condensate at $50 \%$ water-cut and 3 wt $\%$ AA-LDHI.

The AA-LDHI is allowing in these conditions to easily transport formed hydrates at a concentration of $28 \%$ Hydrates in Liquid (corresponding to a water-to-hydrate conversion of $54 \%$ ). The maximum pressure loss measured when the hydrates slurry is formed reached 5.6 bar, which is corresponding to a dynamic viscosity of $200 \mathrm{mPas}$. At $\mathrm{t}=72 \mathrm{~h}$, various flowrates were performed in order to determine the behavior of the formed hydrates slurry with AA-LDHI: it was shown that this slurry is fully Newtonian (i.e. presenting a constant viscosity whatever the shear rate), demonstrating the hydrates were well dispersed in these conditions. This result is consistent with these obtained previously on the stirred-tank reactor with the CP hydrates and the gas hydrates.

\section{Conclusion}

$\mathrm{CP}$ hydrates and $\mathrm{CH}_{4} / \mathrm{C}_{3} \mathrm{H}_{8}$ hydrates formation was studied at a quiescent water/oil interface without and in the presence of AA-LHDI. With $0.1 \mathrm{wt} \%$ AA-LHDI, the hydrates formed water-wettable hollow conical crystals with their vertex pointing in the aqueous phase. The crystals were water-wettable.

The anti-agglomeration performance experiments on CP hydrates showed that the system with 1 wt $\%$ AA-LDHI was composed of dispersed hydrate particles (about $400 \mu \mathrm{m}$ ) in the CP phase. A good correlation was found between the wettability of the hydrate crystals formed in agitated reaction and the quiescent water/CP phase. In the case of $\mathrm{CH}_{4} / \mathrm{C}_{3} \mathrm{H}_{8}$ hydrates, the same trends were observed. The addition of $1 \mathrm{wt} \%$ AA LHDI allows the formation of a flowable hydrate slurry in these conditions.

Complementary tests were performed using a semi-industrial flow loop with a real condensate and with a $\mathrm{CH}_{4} / \mathrm{C}_{3} \mathrm{H}_{8}$ gas mix at 50 bar and $50 \%$ water-cut and at $9{ }^{\circ} \mathrm{C}$ subcooling with $3 \mathrm{wt} \%$ AA-LDHI: results confirmed the good transportability of the formed hydrates in these conditions. The laboratory AA performance evaluation and the semi-industrial test gave consistents results on the good AA performance of the AA-LDHI.

Despite of the unusual water wettability of the hydrate particles in the presence of AA-LDHI, this antiagglomerant shows very good AA performance, probably due to the low interfacial tension between the oil phase and water phase it induces and steric and/or electrostatic repulsions between the particles. 


\section{Acknowledgments}

The authors are grateful to Arkema for the support of this work and for the supplying of the AA-LHDI. The authors wish to acknowledge Total S.A. for their support and for allowing to publish these results.

\section{References}

1. Sloan, E.D.; Koh, C. A. Clathrate hydrates of natural gases, 3rd ed. CRC Press, Taylor \& Francis Group, Boca Raton, FI, 2008.

2. Kelland, M. A. Production chemicals for the oil and gas industry. CRC Press, Taylor \& Francis Group, Boca Raton, FL, 2009.

3. Delroisse, H.; Plantier, F.; Marlin, L.; Dicharry, C.; Frouté, L.; André, R.; Torré, J.-P., J. Chem. Thermodynamics, 2018, 125, 136-141.

4. Li, X.; Negadi, L.; Firoozabadi, A., Energy Fuels 2010, 24, 4937-4943.

5. Abojaladi, N. and Kelland, M. A., Chem. Eng. Sci. 2016, 152, 746-753.

6. Delroisse, H.; Torré, J.-P.; Dicharry, C., Energy Fuels 2018, 32 (12), 12277-12288.

7. Mitarai, M.; Kishimoto, M.; Suh, D.; Ohmura, R. Cryst. Growth Des. 2015, 15, 812-821.

8. Karanjkar, P. U.; Lee, J. W.; Morris, F. F., Cryst. Growth Des. 2012, 12, 3817-3824.

9. Delroisse, H.; Torré, J.-P.; Dicharry, C. Cryst. Growth Des. 2017, 17, 5098-5107.

10. Yoslim, J.; Linga, P.; Englezos, P. J. Cryst. Growth 2010, 313, 68-80.

11. Lo, C.; Couzis, A.; Soumasundaran, P.; Lee, J. W.; Zhang, J. S., J. Phys. Chem. C 2010, 114, 13385-13389.

12. Huo, Z.; Freer, E.; Lamar, M.; Sannigrahi, B.; Knauss, D. M.; Soan Jr., E. D., Chem. Eng. Sci, 2001, 56, 4979-4991.

13. York J. D. et Firoozabadi, A., J. Phys. Chem. B 2008a, 112, 10455-10465.

14. Zhao, H.; Sun, M.; Firoozabadi, A., Fuel 2016, 180, 187-193.

15. Peng, B.-Z.; Chen, J.; Sun, C.-Y.; Dandekar, A.; Guo, S.-H.; Liu, B.; Mu, L.; Yang, L.-Y.; Li, W.Z.; Chen, G.-J., Chem. Eng. Sci. 2012, 84, 333-344.

16. Pham, T.-K.; Cameirao, A.; Herri, J.-M.; Glenat, P., Experimental study on methane hydrate formation and transport from emulsion in a "gas lift" rise in a flowloop, ICGH 9 conference, 2017, Denver, USA.

17. Peytavy J.L., Glénat P., Bourg P., Qualification of Low Dose Hydrate Inhibitors (LDHIs): field cases studies demonstrate the good reproducibility of the results obtained from flow loops. Proceedings of ICGH 6 conference, 2008, Vancouver, Canada.

18. Aman, Z. M.; Sloan, E.D.; Sum, A. K.; Koh, C. A., Phys. Chem. Chem. Phys. 2014, 16, 25121-25128.

19. T. E. Pou; F. Moser; G. Barreto; J.-P. Gillet, US Patent 0346790, 2018.

20. Høiland S., Borgund A.E., Glénat P., Fotland P., Askvik K., Xiaoyun L., The wetting index: $a$ quantitative measure of indigenous hydrate plugging tendency; flow test validations. Proceedings of ICGH 7 conference, 2011, Edinburgh, Scotland, UK.

21. Sakemoto, R.; Sakamoto, H.; Shiraiwa, K.; Ohmura, R.; Uchida, T., Cryst. Growth Des. 2010, 10, 1296-1300.

22. Anklam, M. R.; York, J. D.; Helmerich, L.; Firoozabadi, A., AIChE J. 2008, 54, 565-574.

23. Taylor, C. J.; Dieker, L.; Miller, K.T.; Koh, C.A.; Sloan Jr., E. D., J. Colloid Interface Sci. 2007, 306, 255-261.

24. Brown, E.P.; Hu, S.; Wells, J.; Wang, X.; Koh, C. Energy Fuels 2018, 32, 6619-6626. 